\title{
Universiteit
}

Leiden

The Netherlands

\section{The Criminal Case Processing of Foreign Nationals in the Netherlands}

Light, M.T.; Wermink, H.T.

\section{Citation}

Light, M. T., \& Wermink, H. T. (2021). The Criminal Case Processing of Foreign Nationals in the Netherlands. European Sociological Review, 37(1), 104-120.

doi:10.1093/esr/jcaa039

Version: $\quad$ Publisher's Version

License: $\quad$ Leiden University Non-exclusive license

Downloaded from: $\quad$ https://hdl.handle.net/1887/137286

Note: To cite this publication please use the final published version (if applicable). 


\title{
The Criminal Case Processing of Foreign Nationals in the Netherlands
}

\section{Michael T. Light ${ }^{1}$ and Hilde Wermink ${ }^{2, *}$}

${ }^{1}$ Department of Sociology, University of Wisconsin-Madison, Madison, WI 53706, USA and ${ }^{2}$ Department of Criminology, Institute for Criminal Law and Criminology, Leiden University, P0 Box 9520, 2300 RA Leiden, The Netherlands

${ }^{*}$ Corresponding author. Email: h.t.wermink@law.leidenuniv.nl

Submitted October 2019; revised May 2020; accepted June 2020

\begin{abstract}
Foreign nationals are increasingly encountering the criminal justice institutions of many European countries. Yet, basic questions about how they are punished within these institutions, particularly at the early stages of case processing, remain unanswered. This article combines linked case information from arrest through sentencing with interviews of Dutch judges and prosecutors to fill this gap. Our findings reveal considerable unexplained citizenship disparities in multiple case outcomes. Compared to Dutch citizens arrested for the same crimes and with similar criminal records, foreign nationals are more likely to have their cases referred to court, to be detained, convicted, and imprisoned. The interviews identified several mechanisms that explicate these differences, including (i) annoyance when foreign nationals are perceived to be in the country for the purpose of committing crime; (ii) logistical issues when noncitizens do not have a permanent residence, and; (iii) undermining the need for reintegration because many defendants are unlikely to remain in the Netherlands.
\end{abstract}

\section{Introduction}

Substantial increases in immigration have become an intense source of debate and controversy across Western societies, pushing the study of citizenship and state responses to migration to the fore of sociological inquiry. Against this backdrop, a growing body of sociolegal research has documented the increasingly punitive turn towards noncitizens, whereby governments across Europe have significantly expanded the role of the criminal justice system to regulate mobility (Aas and Bosworth, 2013). As a result, there is growing recognition that foreign nationals are funnelled into the penal institutions of many European countries (van der Woude and van der Leun, 2017). Yet, there remains a surprising lack of analysis as to how noncitizens fare within these institutions (but see Light, 2016). ${ }^{1}$

This is a significant gap given that prior research identifies conflicts over national belonging as the 'key driving force of penal sanctioning in the context of globalization' (Barker 2012: p. 118). In line with this view, there has been a dramatic increase in the number of foreign inmates-in both absolute and relative termsincarcerated throughout Europe. At over 150,000 current inmates, foreign nationals are vastly overrepresented in many of the prison systems of Europe, particularly Western Europe. For instance, the share of 
foreign inmates in the prison population is well above the European median (16\%) in Austria (55\%), France $(22 \%)$, Germany $(38 \%)$, Greece $(53 \%)$, Italy $(34 \%)$, Switzerland (71\%), and Spain (28\%). In the Netherlands, while noncitizens account for only 5 per cent of the total population, they represent nearly 20 per cent of all prisoners (Aebi et al., 2018). The extent to which these disparities reflect differences in criminal conduct as opposed to differential treatment, however, remains an open question. Addressing this sociological blind spot is critical considering that a criminal conviction 'has a far greater and more deleterious ramification for non-nationals than ever before' (Bosworth, 2011: pp. 591-592).

In this article, we address this gap using a unique combination of criminal case and interview data to examine the punishment of foreign nationals within the criminal justice system of the Netherlands. In doing so, we address two critical empirical shortcomings in prior research.

The first concerns the overreliance on postconviction data. Much of the sentencing research, including those studies focused on non-citizens (Light, Massoglia and King, 2014), drawn from samples of individuals that have been selected through conviction. Consequently, we know virtually nothing about the treatment of foreign nationals in the highly discretionary and negotiated processes that occur prior to sentencing, such as charging, conviction, and prosecutorial recommendations. Thus, additional case information is needed to investigate issues of selection across the stages of criminal case processing as well as shed light on the cumulative disparity between citizens and foreign nationals throughout the criminal justice system. We address this limitation by using a nationally representative sample of linked files from the Dutch Public Prosecutor's Office that tracks individual cases from arrest through final adjudication. Using this data, we investigate whether otherwise similar citizen and non-citizen arrestees receive different outcomes at multiple key stages in case processing, such as the decision to charge, the likelihood of conviction, and incarceration.

The second relates to the relative paucity of mixedmethods studies and the inability of quantitative data to identify the underlying mechanisms that result in disparate punishment outcomes. To address this concern, we draw from detailed interviews with both prosecutors and judges in the Netherlands to capture the complexity of decision-making and to explicate the overt and subtle processes through which foreign nationals may receive differential punishment. Taken together, this article provides the first study of the citizenship-punishment nexus that captures the complete picture of each individual's path through the criminal justice system using both quantitative and qualitative data.

\section{Citizenship and Punishment}

The study of punishment and inequality forms a central plank in the sociological and criminological analysis. Within this body of work, perhaps no subject has received more attention than unwarranted disparities in legal decision-making. A unifying theme of this research is that punishment decisions are susceptible to factors beyond legally relevant criteria. For instance, multiple theoretical accounts suggest that negative attributions and stereotypes may be used as external cues to gauge critical elements of case processing, such as determining blameworthiness and assessing dangerousness (Steffensmeier, Ulmer and Kramer, 1998). The work in this vein, however, has largely focused on markers that traditionally stratify within societies, such as race, class, and gender. As a result, the punishment of foreign nationals remains undertheorized because 'most sociologists of punishment and imprisonment remain wedded to a nationalist vision of state control, one unaffected by growing transnational flows and mobility' (Bosworth and Kaufman, 2011: p. 430). With over 250 million international migrants globally (United Nations, 2017), this approach is no longer tenable. By presuming a bounded national polity, previous research not only omits a potentially critical axis of contemporary legal inequality but also elides a serious engagement with the ways mass mobility alters the goals of punishment (Bosworth, 2019).

According to Sayad (2004), the punishment of migrants is inextricably tied to the cultural, political, and normative boundaries that define national membership and exclude 'foreigners'. Thus, rather than being used as a 'cue' for punitiveness, lack of national membership may be more directly linked to punishment considerations, ultimately resulting in what Sayad (2004) refers to as 'double punishment', though it may be more aptly described as 'harsher punishment': ${ }^{2}$

The fact of being an immigrant delinquent constitutes, as a general rule, something of an aggravating circumstance...Before we can even speak of racism or xenophobia, the notion of 'double punishment' is therefore present within any judgment passed on the immigrant. It is rooted in state thought. . All immigrant behaviour, and especially deviant behaviour, has repercussions on the phenomenon of immigration itself, and leads to greater disapproval, greater 
disqualification, and greater stigmatization. [Some] do not conceal or hide their satisfaction at seeing two different modalities of crime and the two punishments that sanction them overlapping and aggravating one another - in their view, this is only fair, and basically, something that is quite right and that should be the rule...(Sayad 2004: pp. 282-285).

Based on this view, state institutions and legal actors will be more punitive against the criminality of noncitizens. In line with this perspective, analyses of postconviction data in the U.S. and Germany demonstrate that non-citizens receive harsher sanctions than comparable citizens (Light, Massoglia and King, 2014; Light, 2016).

Transnational mobility also raises logistical challenges that may lead to harsher penalties for foreign nationals. This is particularly the case for those noncitizens who cannot document residency in the host society. For instance, the ability to collect fines or complete the terms of probation are often dependent on the courts' ability to monitor individuals. And the implementation of community sanctions becomes problematic, and in some cases moot, when defendants are unlikely to return to the society in which they are convicted. Indeed, Dutch prosecutorial guidelines recommend against certain community sanctions such as work penalties for irregular migrants, those likely to lose their residency, or those likely to be officially deemed 'persona non grata' (van Kalmthout et al., 2007; Boone and Kox, 2012). This may be salient in the Netherlands, where more than 18 million tourists visit annually and migrants commit a significant amount of crime (Unnever, 2018). Thus, the fact that non-citizens are more likely to be mobile may place practical constraints on considering monetary or probationary sentences, resulting in more imprisonment sanctions.

Though perhaps pragmatic, the consideration of national membership in criminal case processing represents a fundamental shift in the traditional goals of punishment. In the Netherlands and throughout Europe generally, criminal punishment is meant to serve varied aims, including retribution, deterrence, and enhanced public safety (Tak, 2008). In addition, rehabilitation (or resocialization) is generally considered a fundamental principle of sentencing and corrections. Indeed, Article 6 of the European Prison Rules states 'all detention shall be managed so as to facilitate the reintegration into free society of persons who have been deprived of their liberty'. This norm is further codified in the Article 2 paragraph 2 of the Dutch Penitentiary Principles Act, which obligates the government to ensure that penal sanctions are administered in a way that prepares the defendant to successfully re-enter society.

When penal power is exercised over non-state members, however, this rationale is undermined. As Aas (2014: p. 521) describes, 'the absence of formal membership is the essential factor contributing towards the shifting nature of penal intervention from reintegration into the society towards territorial exclusion, and towards the development of a particular form of penality...bordered penality'. The central criterion for this new form of justice is the erosion of one of the central pillars of contemporary penal ideology in Europe-the resocialization of the offender. As a result, the contours of criminal justice are increasingly dependent on assessments of who has the right to be in the country. For citizens, criminal case processing operates within the ordinary logics that encompass all of the goals of punishment. For many foreign nationals, however, a parallel system operates under a different logic; one where the least coercive goal-reintegration-is largely absent. This bifurcation of case processing would anticipate more inclusive sanctions for citizens (e.g. deferred adjudications, fines, and community sanctions) and more exclusive sanctions (e.g. imprisonment) for noncitizens.

\section{Data}

Taken together, our review of the theoretical literature suggests multiple pathways through which foreign nationals are likely to receive more punitive outcomes throughout case processing. We test this hypothesis using individual-level data from Dutch criminal courts. This is a particularly stringent test given that the Netherlands has a strong rule of law tradition that protects the rights of the accused regardless of citizenship (van Kalmthout et al., 2007).

The court records come from the Research and Documentation Centre (WODC) ${ }^{3}$ of the Netherlands Ministry of Justice (MOJ) and contain information on a $10 \%$ representative sample of all criminal cases registered at the Public Prosecutor's Office in 2012, yielding 18,274 cases. Important for our inquiry, this sample was limited to non-immigration cases because Dutch citizens are not at risk of sanctioning for the bulk of immigration violations. From this original sample, we impose several additional restrictions. All juvenile offenses are excluded $(N=1,745)$ because they are governed by special provisions in the criminal code. We also omit misdemeanours and traffic violations $(N=3,997)$ as well as cases where the defendant's citizenship is unknown $(N=654)$, yielding a final analytical sample of 11,878 individuals who were arrested and referred for prosecution. This is a 


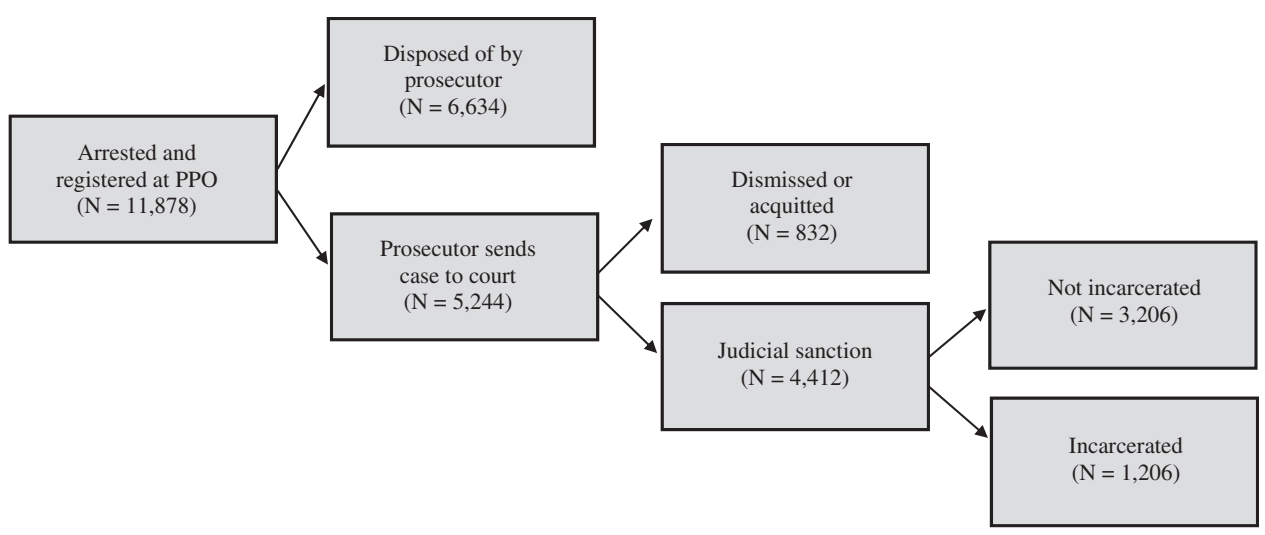

Figure 1. Disposition of criminal cases in the Netherlands.

rich, yet surprisingly underutilized data source as it contains detailed information on the entire universe of cases that have led to any type of prosecutorial or judicial action in the Netherlands, including dismissal, thus providing a rare opportunity to examine the treatment of foreign nationals across a range of case decisions. Measurement properties for all variables are shown in Supplementary Table SA1.

\section{Dependent Variables}

The Dutch criminal justice system is characterized by substantial discretionary powers and a wide array of sanctioning options. Of particular interest is the twotrack sentencing system driven by prosecutorial discretion, as shown in Figure 1. When an individual is arrested and referred for prosecution, a prosecutor first has to decide whether to dispose of the case herself or send the case to court because it potentially warrants more severe punishment. Under Dutch law, prosecutors lack the authorization to impose prison sentences so cases that are handled by the prosecutor avoid the process of a full criminal trial and receive relative leniency. We capture this initial prosecutorial decision with a dichotomous variable $(1=$ case sent to court; $0=$ case disposed by the prosecutor). For those cases that are sent to court, the next stage of case processing is either conviction or acquittal/dismissal $(1=$ convicted $)$. From there, we look at the incarceration decision $(1=$ prison $)$ and lastly, the length of incarceration, measured in days. Individuals who did not receive a prison sentence because they were either never charged or not convicted were assigned a value of 0 days of incarceration, as were those who were convicted in court but not imprisoned.

In total, we examine the punishment of foreign nationals across four different dependent variables. And it is important to note that the two initial decisions would be entirely hidden from traditional postconviction analyses, as would the majority of criminal cases given that nearly two-thirds of arrested individuals were never convicted in a criminal court (only 37 per cent of cases received a judicial sanction).

\section{Focal Independent Measure}

Our primary independent variable is the arrestee's citizenship status. Data files from the WODC do not typically contain measures of citizenship. However, after a review for scientific merit, we were granted access to restricted citizenship information from the Dutch Judicial Information Service. These data were then merged to court records specifically for the purposes of this study. We code defendants as either Dutch citizens or non-Dutch citizens. In subsequent models, we investigate heterogeneity among both citizens and noncitizens by further classifying defendants based on their country or region of origin (described below).

\section{Offender, Case, and Offense-Related Variables}

Previous research consistently demonstrates that the severity of the offense and the arrestee's criminal history are critical determinants of prosecutorial and judicial decision-making. We capture the seriousness of the criminal conduct with two discrete measures: the total number of criminal charges and the overall severity of the offense based on the statutory maximum penalty $(1=$ less than 4 years of imprisonment; $2=$ between 4 and 8 years; $3=$ greater than 8 years) (c.f. Wermink et al., 2015). This latter measure is critical as it captures legal and statutory differences that distinguish serious and minor crimes within and across each offense category. Criminal history is measured with two distinct variables: the total number of prior convictions and, to 
more effectively distinguish those with serious criminal backgrounds, a dichotomous indicator for whether the defendant was previously incarcerated $(1=$ yes). In addition to influencing case processing, prior criminality factors into Dutch naturalization law. ${ }^{4}$ Thus, measures of criminal history are essential for comparing the cases of citizens and foreign nationals. Previous research also demonstrates that the type of offense is consequential for case processing. We thus include dummy variables for 14 different offense types that cover a range of property, violent, and drug offenses (see Supplementary Appendix for a detailed list). ${ }^{5}$

Regarding offender attributes, we include controls for the age and sex of arrestees $(1=$ female). Previous research suggests that national origin may be consequential in Dutch courts and 30 per cent defendants in our sample are foreign-born (Wermink Hilde et al., 2018). We thus account for the place of birth to separate national membership from the national origin by distinguishing arrestees born in the Netherlands from those born in Morocco, the Netherlands Antilles, Suriname, Turkey, other European countries, other 'Western' countries, ${ }^{6}$ non-Western countries, and those whose place of birth is unknown.

\section{Analytical Strategy}

\section{Quantitative analysis}

We estimate logistic regressions for each of the early case processing decisions, including the type of disposition, conviction, and incarceration. The length of imprisonment is modelled using two distinct methods. First, in line with much of the prior sentencing literature, we first examine disparities in sentence lengths using ordinary least squares (OLS) regression. ${ }^{7}$ Though commonplace in the punishment field and no-doubt informative, there are two potential limitations of standard OLS approaches for our study. The first is empirical. The nature and non-normal distribution of sentences in our data suggest alternative techniques may be more appropriate. Criminal sentences are essentially counts of the number of days an offender is ordered imprisoned and prison sanctions in the Netherlands are infrequent. Indeed, a full 90 per cent arrestees in our study were never ordered incarcerated. As a result, both the mode and median of sentence length is zero and the measure is characterized by extreme positive skew. Moreover, there is an indication of overdispersion in our data, as the variance of sentence length is nearly eight times larger than the mean. Under these circumstances, OLS techniques can yield 'inefficient, inconsistent, and biased estimates' (Long, 1997: p. 217). To address this concern, our second approach utilizes zero-inflated negative binomial regressions (ZINB).

Zero-inflated models account for excess zeros by estimating sentence length as a two-stage process. In doing so, it addresses the second shortcoming of OLS models in sentencing; the inability to separate disparities in sentence length from disparities in earlier case decisions. The first equation estimates the factors that produce zero counts and assumes that this population consists of two subgroups: one that is never at risk of the outcome of interest, often referred to as 'structural' zeros, and another for which a positive account may or may not occur (Cameron and Trivedi, 2013). In our case, those who were either never referred to a court, were acquitted, or had their cases dismissed would be considered structural zeros in that only those convicted are at risk of a prison sanction. Those convicted but not incarcerated would be the second group of zeros. Zero-inflated models simultaneously estimate a binary inflation equation that produces 'excess zeros' in addition to a negative binomial model for the remaining counts. In this regard, we can observe whether sentencing disparities occur before the incarceration decision, after, or both. In all models, we control for the judicial district to account for any potential inter-jurisdictional policy or decision-making differences and we use clustered standard errors to adjust for unmeasured interdependence within the same district.

Combined, the statistical analysis provides important insights into the treatment of foreign nationals in several key prosecutorial and judicial decisions as well as the aggregate disparity between citizen and noncitizen arrestees throughout criminal case processing. One shortcoming of purely quantitative approaches, however, is the inability to identify the intervening mechanisms that yield disparate sentences. Moreover, statistical analyses provide limited insight into the ways in which criminal justice actors themselves consider the unique challenges posed by noncitizen defendants in their day-to-day decision-making. We thus draw on semi-structured interviews with both prosecutors and judges in the Netherlands to shed light on this critical area of inquiry.

\section{Qualitative analysis}

The interviews were conducted between June 2016 and November 2017 in two large cities in the Netherlands. Within these districts, non-Dutch nationals comprise a considerable amount of the case docket. Moreover, both research sites are home to a diverse population of immigrants, thus providing ideal locations to discuss the role 
of national membership orthogonal to any specific nationality. In total, we interviewed nine sitting judges and seven criminal prosecutors (see Supplementary Appendix for details on participant recruitment). It is important to delineate the scope of these interviews. Rather than providing representative accounts that capture the general views of all judges or prosecutors within these districts, the primary aim was to leverage the social position of these criminal justice actors to provide strategic knowledge about the case processing of foreign defendants. For this reason, the interviews primarily focused on three key themes:

Case processing: features of charging, trial, and sentencing procedures that may differ for Dutch and nonDutch nationals.

- Views on criminality: perspectives on whether crimes committed by noncitizens are dissimilar than those committed by citizens.

- Key charging and sentencing considerations: the elements that factor into deciding prison vs. community/financial sanctions, and the extent to which citizenship factors into these considerations.

This mixed-methods approach serves two primary aims. Not only does it avoid oversimplifying the statistical results by capturing the interpretive processes involved in punishing foreign nationals, it also provides considerable depth and nuance by making any potential legal disparities visible in real contexts. In this regard, our analytical strategy is well positioned to answer calls for researchers to 'develop deeper insights into the dynamics and complexities that foster' legal inequality for foreign nationals (van der Woude, van der Leun and Nijland, 2014: p. 575).

\section{Quantitative Results}

\section{Descriptive Statistics}

Table 1 displays the descriptive statistics for the total sample and then separately by citizenship status. Highlighting the importance of studying early case decisions, the majority $(56 \%)$ of cases are never sent to court, meaning that a prosecutor disposes of them rather than a judge. This is not the case for foreign citizens, however, where 56 per cent of cases were referred to courts. In line with theoretical expectations, we observe similar disparities in the conviction, incarceration, and sentence length outcomes. Nearly half of foreign arrestees are convicted in a criminal court and no less than 25 per cent of foreign citizens were incarcerated. For Dutch citizens, only 36 per cent were convicted and just 8 per cent received a prison sentence. In terms of the length of imprisonment, the average incarceration sentence for foreign citizens was nearly double that of Dutch citizens. What explains these differences, however, is unclear. Relative to Dutch citizens, foreign nationals are more likely to be male, to have been previously incarcerated, and to have more severe cases. Thus, we turn to our multivariate analysis to assess whether differences in case processing remain after controlling for these confounding factors.

\section{Disparities in Early Case Processing Decisions}

We begin with the initial prosecutorial decision to send a case to court in model 1 of Table 2. Before turning to our focal results, we note that the pattern of findings for the control measures is entirely consistent with extant research on criminal sanctioning; male arrestees, those with more severe cases, who have a prior prison spell, and are charged with more offenses are all more likely to have their cases referred to court.

Turning to our primary focus, the odds of having a case sent to court are over one and half times higher for foreign nationals than Dutch citizens, net of controls for offense type and severity, criminal history, and other key defendant characteristics. To put this in context, this unexplained disparity is on par with or exceeds the effects of other socio-demographics featured prominently in prior work, including national origin and gender. This offers suggestive evidence that the overrepresentation of foreign citizens in the incarcerated population is partially due to the fact they are more likely to be placed 'at risk' for prison after their initial case review. And it is important to note that the gap between citizens and noncitizens is not simply a substitute for national origin distinctions, as additional analyses demonstrate that foreign nationality explains nearly all of the country of birth disparities, whereas country of birth explains virtually none of the citizenship differences. ${ }^{8}$

There is an equally sizeable disparity disfavouring foreign nationals in the likelihood of conviction. According to model 2, the odds of conviction for nonDutch arrestees are 1.6 times higher than for Dutch citizens. Turning to the incarceration decision in model 3, the punishment gap between citizens and foreign nationals widens considerably. Ceteris paribus, the odds of imprisonment for non-Dutch arrestees are nearly three times higher. This difference is roughly equivalent to a prior stint in prison.

Combined, the results in Table 2 align with the theoretical argument that foreign nationals face harsher penalties at multiple decision points in case processing. 
Table 1. Descriptive statistics per citizenship status

\begin{tabular}{|c|c|c|c|c|c|c|}
\hline \multirow{3}{*}{ Dependent variables } & \multirow{2}{*}{\multicolumn{2}{|c|}{$\begin{array}{l}\text { Total sample } \\
N=11,878\end{array}$}} & \multirow{2}{*}{\multicolumn{2}{|c|}{$\begin{array}{l}\text { Dutch } \\
N=8,832\end{array}$}} & \multirow{2}{*}{\multicolumn{2}{|c|}{$\begin{array}{l}\text { Foreign } \\
N=1,379\end{array}$}} \\
\hline & & & & & & \\
\hline & Mean & S.D. & Mean & S.D. & Mean & S.D. \\
\hline Prosecutor sends case to court & 0.44 & 0.50 & 0.43 & 0.49 & 0.56 & 0.50 \\
\hline Any judicial conviction & 0.37 & 0.48 & 0.36 & 0.48 & 0.49 & 0.50 \\
\hline Any incarceration & 0.10 & 0.30 & 0.08 & 0.27 & 0.25 & 0.43 \\
\hline Prison length & 24.85 & 192.07 & 20.46 & 184.82 & 43.02 & 239.46 \\
\hline \multicolumn{7}{|l|}{ Social demographics } \\
\hline Netherlands & 0.70 & 0.46 & 0.78 & 0.41 & 0.06 & 0.23 \\
\hline Morocco & 0.03 & 0.17 & 0.02 & 0.14 & 0.29 & 0.29 \\
\hline Netherlands Antilles & 0.03 & 0.18 & 0.04 & 0.19 & 0.00 & 0.00 \\
\hline Suriname & 0.04 & 0.21 & 0.05 & 0.21 & 0.03 & 0.16 \\
\hline Turkey & 0.03 & 0.16 & 0.02 & 0.14 & 0.08 & 0.26 \\
\hline European country & 0.06 & 0.24 & 0.01 & 0.10 & 0.42 & 0.49 \\
\hline Other non-Western country & 0.07 & 0.26 & 0.06 & 0.24 & 0.17 & 0.38 \\
\hline Other Western country & 0.03 & 0.17 & 0.02 & 0.13 & 0.11 & 0.31 \\
\hline Unknown country & 0.01 & 0.07 & 0.00 & 0.01 & 0.04 & 0.20 \\
\hline Age & 34.88 & 13.52 & 35.11 & 13.85 & 33.11 & 10.55 \\
\hline Female & 0.22 & 0.41 & 0.22 & 0.41 & 0.18 & 0.39 \\
\hline \multicolumn{7}{|l|}{ Criminal history } \\
\hline No.of convictions & 3.11 & 5.67 & 3.23 & 5.76 & 2.20 & 4.81 \\
\hline Prior prison sentence & 0.21 & 0.41 & 0.21 & 0.41 & 0.23 & 0.42 \\
\hline \multicolumn{7}{|l|}{ Case characteristics } \\
\hline No. of crimes & 1.31 & 0.82 & 1.31 & 0.82 & 1.30 & 0.86 \\
\hline Mild case & 0.25 & 0.43 & 0.26 & 0.44 & 0.19 & 0.39 \\
\hline Severe case & 0.68 & 0.47 & 0.68 & 0.47 & 0.72 & 0.45 \\
\hline Very severe case & 0.07 & 0.25 & 0.07 & 0.25 & 0.09 & 0.29 \\
\hline \multicolumn{7}{|l|}{ Offense type } \\
\hline Theft & 0.14 & 0.35 & 0.14 & 0.34 & 0.19 & 0.39 \\
\hline Sex & 0.02 & 0.15 & 0.02 & 0.15 & 0.01 & 0.12 \\
\hline Threatening & 0.05 & 0.22 & 0.05 & 0.22 & 0.03 & 0.16 \\
\hline Assault & 0.17 & 0.37 & 0.17 & 0.38 & 0.11 & 0.31 \\
\hline Other violent & 0.02 & 0.13 & 0.02 & 0.13 & 0.01 & 0.11 \\
\hline Aggravated theft & 0.10 & 0.30 & 0.09 & 0.28 & 0.17 & 0.37 \\
\hline Other property & 0.09 & 0.28 & 0.09 & 0.28 & 0.09 & 0.28 \\
\hline Drug & 0.07 & 0.26 & 0.07 & 0.25 & 0.11 & 0.31 \\
\hline Firearms & 0.02 & 0.14 & 0.02 & 0.14 & 0.02 & 0.15 \\
\hline Public order & 0.08 & 0.27 & 0.08 & 0.27 & 0.06 & 0.24 \\
\hline Destruction & 0.05 & 0.21 & 0.05 & 0.22 & 0.03 & 0.16 \\
\hline Forgery & 0.03 & 0.17 & 0.02 & 0.15 & 0.07 & 0.25 \\
\hline Other & 0.16 & 0.37 & 0.17 & 0.38 & 0.11 & 0.31 \\
\hline Unknown & 0.01 & 0.09 & 0.01 & 0.09 & 0.01 & 0.09 \\
\hline
\end{tabular}

We examine the extent to which these disadvantages accumulate into sentence length differences in Tables 3 and 4 .

\section{Aggregate Disparities in Sentence Lengths}

Table 3 presents the results from the more traditional OLS model. The citizenship coefficient represents the aggregate unexplained disparity in sentences that appear to be introduced in case processing after the initial arrest. With the inclusion of legally relevant factors, noncitizens receive 47 per cent longer sentences than their Dutch counterparts. This corresponds to an unexplained gap of approximately 6 days. ${ }^{9}$ The source of this disparity, however, is opaque. Is it that similarly situated convicted foreign nationals receive longer terms of imprisonment? Or is that equivalent noncitizen arrestees 
Table 2. Logistic regression models of early case processing decisions

\begin{tabular}{|c|c|c|c|c|c|c|c|c|c|}
\hline \multirow[b]{4}{*}{ Variables } & \multicolumn{3}{|c|}{ Model 1} & \multicolumn{3}{|c|}{ Model 2} & \multicolumn{3}{|c|}{ Model 3} \\
\hline & \multicolumn{3}{|c|}{ Send to court } & \multicolumn{3}{|c|}{ Judicial conviction } & \multicolumn{3}{|c|}{ Incarceration } \\
\hline & \multicolumn{3}{|c|}{$(N=11,878)$} & \multicolumn{3}{|c|}{$(N=11,878)$} & \multicolumn{3}{|c|}{$(N=11,878)$} \\
\hline & b & SE & OR & b & SE & OR & b & SE & OR \\
\hline \multicolumn{10}{|l|}{ Citizenship status } \\
\hline \multicolumn{10}{|l|}{ Dutch (ref.) } \\
\hline Foreign & 0.46 & 0.12 & $1.58^{* * * *}$ & 0.47 & 0.11 & $1.61^{* * * *}$ & 1.01 & 0.30 & $2.74^{* * *}$ \\
\hline \multicolumn{10}{|l|}{ Social demographics } \\
\hline \multicolumn{10}{|l|}{ Netherlands (ref.) } \\
\hline Morocco & -0.01 & 0.19 & 0.99 & -0.15 & 0.16 & 0.86 & 0.07 & 0.34 & 1.07 \\
\hline Netherlands Antilles & 0.41 & 0.14 & $1.51^{* * *}$ & 0.43 & 0.15 & $1.54^{* * *}$ & 0.95 & 0.30 & $2.58^{* * *}$ \\
\hline Suriname & 0.20 & 0.10 & $1.22^{*}$ & 0.12 & 0.11 & 1.13 & 0.35 & 0.24 & 1.42 \\
\hline Turkey & 0.06 & 0.16 & 1.07 & -0.14 & 0.12 & 0.87 & -0.03 & 0.26 & 0.97 \\
\hline European country & 0.11 & 0.20 & 1.11 & 0.08 & 0.18 & 1.08 & 0.71 & 0.29 & $2.03^{*}$ \\
\hline Other non-Western country & 0.09 & 0.09 & 1.09 & 0.00 & 0.10 & 1.00 & 0.50 & 0.22 & $1.65^{*}$ \\
\hline Other Western country & 0.08 & 0.13 & 1.08 & 0.07 & 0.14 & 1.07 & 0.54 & 0.24 & $1.72^{*}$ \\
\hline Unknown country & 0.50 & 0.40 & 1.65 & 0.32 & 0.45 & 1.38 & 1.16 & 0.57 & $3.20 *$ \\
\hline Age & -0.01 & 0.00 & $0.99^{* * *}$ & -0.01 & 0.00 & $0.99^{* * *}$ & -0.02 & 0.00 & $0.98^{* * *}$ \\
\hline Female & -0.32 & 0.05 & $0.73^{* * * *}$ & -0.39 & 0.05 & $0.68^{* * * *}$ & -0.73 & 0.16 & $0.48^{* * *}$ \\
\hline \multicolumn{10}{|l|}{ Criminal history } \\
\hline No. of convictions & 0.08 & 0.01 & $1.08^{* * * * *}$ & 0.06 & 0.01 & $1.06^{* * * * *}$ & 0.05 & 0.01 & $1.06^{* * *}$ \\
\hline Prior prison sentence & 0.46 & 0.07 & $1.58^{* * *}$ & 0.46 & 0.07 & $1.58^{* * * *}$ & 1.00 & 0.10 & $2.71^{* * x}$ \\
\hline \multicolumn{10}{|l|}{ Case characteristics } \\
\hline No. of crimes & 0.73 & 0.06 & $2.07^{* \ldots *}$ & 0.48 & 0.06 & $1.61^{* * n}$ & 0.44 & 0.05 & $1.56^{* * x}$ \\
\hline \multicolumn{10}{|l|}{ Mild case (ref.) } \\
\hline Severe case & 0.97 & 0.11 & $2.65^{* * * *}$ & 0.99 & 0.12 & $2.69^{* * *}$ & 1.17 & 0.21 & $3.22^{* * n}$ \\
\hline Very severe case & 1.92 & 0.33 & $6.84^{* * * *}$ & 1.86 & 0.32 & $6.42^{* * * *}$ & 3.64 & 0.38 & $37.98^{* * *}$ \\
\hline Offense effects? & \multicolumn{3}{|c|}{ Yes } & \multicolumn{3}{|c|}{ Yes } & \multicolumn{3}{|c|}{ Yes } \\
\hline District effects? & \multicolumn{3}{|c|}{ Yes } & \multicolumn{3}{|c|}{ Yes } & \multicolumn{3}{|c|}{ Yes } \\
\hline Constant & -2.14 & 0.19 & $0.12^{* * * *}$ & -2.00 & 0.22 & $0.14^{* * *}$ & -4.51 & 0.39 & $0.01^{* * * x}$ \\
\hline Pseudo $R^{2}$ & 0.21 & & & 0.17 & & & 0.37 & & \\
\hline
\end{tabular}

are more likely to reach the incarceration stage? Or is it both?

The results in Table 4, where we model sentence length using a zero-inflated negative binomial model, provide a clear answer: the disparities occur prior to the sentence length decision. Looking at the count model, adjusting for the likelihood of imprisonment, we observe no differences in the sentences for Dutch and non-Dutch citizens. This is not the case when we model the likelihood of incarceration. In the zero-inflated portion of the model, we see a marked gap between citizens and foreign nationals $(b=-1.03)$, meaning that non-citizens are far less likely to receive a non-incarceration sanction. Taken together, the results in Table 4 suggest that the aggregate unexplained punishment gap between citizen and non-citizen arrestees is driven entirely by decisions made prior to the sentence length judgement, thus further underscoring the necessity of information on the early stages of case processing.

\section{Citizenship across Country of Origin Groups}

It is important to consider the scope of our findings. In the case of the Netherlands, the distinction between EU and non-EU foreign nationals is of particular interest. As one of the founding members of the European Union, legal protections for EU defendants are codified in many protocols, conventions, and guidelines; ${ }^{10}$ protections that are both monitored and enforced by the European Court of Justice. These protocols serve the dual purpose of highlighting the unique standing of EU citizens as 
Table 3. OLS regression model of prison length $(N=11,878)$.

\begin{tabular}{|c|c|c|c|}
\hline Variables & $b$ & SE & Exponentiated $b$ 's \\
\hline \multicolumn{4}{|l|}{ Citizenship status } \\
\hline \multicolumn{4}{|l|}{ Dutch (ref.) } \\
\hline Foreign & 0.39 & 0.16 & $1.47^{*}$ \\
\hline \multicolumn{4}{|l|}{ Social demographics } \\
\hline \multicolumn{4}{|l|}{ Netherlands (ref.) } \\
\hline Morocco & 0.02 & 0.13 & 1.02 \\
\hline Netherlands Antilles & 0.37 & 0.12 & $1.44^{* * *}$ \\
\hline Suriname & 0.15 & 0.12 & 1.17 \\
\hline Turkey & -0.01 & 0.09 & 0.99 \\
\hline European country & 0.16 & 0.16 & 1.17 \\
\hline Other non-Western country & 0.13 & 0.07 & $1.14^{*}$ \\
\hline Other Western country & 0.13 & 0.09 & 1.14 \\
\hline Unknown country & 0.31 & 0.30 & 1.36 \\
\hline Age & 0.00 & 0.00 & $1.00^{*}$ \\
\hline Female & -0.14 & 0.03 & $.87^{* * * *}$ \\
\hline \multicolumn{4}{|l|}{ Criminal history } \\
\hline No. of convictions & 0.01 & 0.00 & $1.01^{* * *}$ \\
\hline Prior prison sentence & 0.34 & 0.04 & $1.41^{* * * *}$ \\
\hline \multicolumn{4}{|l|}{ Case characteristics } \\
\hline No. of crimes & 0.29 & 0.03 & $1.33^{* * * *}$ \\
\hline \multicolumn{4}{|l|}{ Mild case (ref.) } \\
\hline Severe case & 0.20 & 0.07 & $1.22^{* * *}$ \\
\hline Very severe case & 2.34 & 0.32 & $10.34^{* * * *}$ \\
\hline Offense effects? & \multicolumn{3}{|c|}{ Yes } \\
\hline District effects? & \multicolumn{3}{|c|}{ Yes } \\
\hline Constant & -0.48 & 0.10 & $0.62^{* * *}$ \\
\hline$R^{2}$ & 0.34 & & \\
\hline
\end{tabular}

$* P<0.05$

$* * 0.01$

$* * * 0.001$. Standard errors are clustered by district. Model includes controls for 14 different offense types and 20 district-specific effects.

well as crystallizing the division between EU and nonEU nationals. Therefore, it is plausible that foreigners from other EU countries may receive less severe punishment compared to non-EU nationals.

We test this possibility in Table 5. Given the significant punishment gap observed at the incarceration stage, we focus analytical attention there. Thus, the specification in model 1 is identical to our prior incarceration model, with the exception that non-citizens are coded as either EU or non-EU nationals. We find little evidence that non-citizens from EU countries receive more lenient treatment in Dutch courts. If anything, the unexplained disparity appears larger for EU citizens, though Wald tests demonstrate these estimates are statistically indistinguishable. Therefore, the results suggest that relative to Dutch citizens, the unexplained sentencing disparities for EU and non-EU nationals are roughly equal.
We further examine the scope of our findings by classifying defendants by their citizenship and country of birth. In model 2, we report incarceration results using a series of dichotomous indicators for each combination of citizenship and place of birth (e.g. Dutch citizens from Morocco, non-Dutch citizens from Morocco, etc.). These fine-grain distinctions align with calls for more nuanced investigations both within and between citizen and non-citizen groups and avoid conflating citizenship status with national origin (Kaufman, 2018). Several notable patterns emerge. First, in line with previous research, we observe sentencing differences among Dutch citizens. Citizens born in non-Western countries and Antilles are more likely to be incarcerated than comparable native-born citizens. For all other Dutch citizen groups, who comprise the majority of non-native citizens, there is no difference in the likelihood of imprisonment conditional on an arrest. ${ }^{11}$ Second, with the exception of those born in the Netherlands, each noncitizen group is more likely to be incarcerated than native Dutch citizens. Stated differently, regardless of national origin, there are significant unexplained punishment disparities for nearly all groups lacking state membership. ${ }^{12}$ Lastly, within national origins, foreign nationals receive more severe dispositions relative to their citizen counterparts. For most groups, these differences are both statistically and substantively significant. ${ }^{13}$ For example, based on the results in model 2, the predicted probability of incarceration for Dutch citizens born in non-Western countries is just 3 per cent. For non-Western defendants without Dutch citizenship, the probability increases more than 3 -fold, to 10 per cent. Thus, the general pattern in models 1 and 2 suggests that the observed punishment gaps between Dutch and non-Dutch citizens are generally applicable across national origin groups.

We further interrogate the distinction between national membership and national origin in model 3 by replicating the incarceration model for only foreignborn arrestees. This approach aligns with research on the 'citizenship premium' characteristic of the broader citizenship literature by comparing foreigners with different citizenship statuses (Bloemraad, 2017). Two findings are germane. First, among the foreign-born, there are few punishment differences across different national-origin groups. Second, we observe a substantively significant unexplained gap whereby foreign nationals are more likely to be incarcerated than similarly situated foreign-born arrestees with Dutch citizenship.

Combined, our quantitative analysis reveals significant disparities between Dutch citizens and foreign 
Table 4. Zero-inflated negative binomial model of sentence length $(N=11,878)$.

\begin{tabular}{|c|c|c|}
\hline & b & SE \\
\hline \multicolumn{3}{|l|}{ Count model } \\
\hline \multicolumn{3}{|l|}{ Citizenship status } \\
\hline \multicolumn{3}{|l|}{ Dutch (ref.) } \\
\hline Foreign & -0.22 & 0.17 \\
\hline \multicolumn{3}{|l|}{ Social demographics } \\
\hline \multicolumn{3}{|l|}{ Netherlands (ref.) } \\
\hline Morocco & 0.42 & 0.34 \\
\hline Netherlands Antilles & -0.26 & 0.15 \\
\hline Suriname & -0.11 & 0.09 \\
\hline Turkey & 0.25 & 0.17 \\
\hline European country & 0.13 & 0.23 \\
\hline Other non-Western country & 0.35 & 0.19 \\
\hline Other Western country & 0.27 & 0.22 \\
\hline Unknown country & 0.00 & 0.34 \\
\hline Age & $0.01^{*}$ & 0.00 \\
\hline Female & $-0.42^{* * *}$ & 0.15 \\
\hline \multicolumn{3}{|l|}{ Criminal history } \\
\hline No. of convictions & -0.01 & 0.01 \\
\hline Prior prison sentence & 0.21 & 0.12 \\
\hline \multicolumn{3}{|l|}{ Case characteristics } \\
\hline No. of crimes & $0.12^{* * * *}$ & 0.03 \\
\hline \multicolumn{3}{|l|}{ Mild case (ref.) } \\
\hline Severe case & 0.19 & 0.51 \\
\hline Very severe case & $1.33^{*}$ & 0.51 \\
\hline Constant & $2.55^{* * * *}$ & 0.71 \\
\hline \multicolumn{3}{|l|}{ Zero-inflated model } \\
\hline \multicolumn{3}{|l|}{ Citizenship status } \\
\hline \multicolumn{3}{|l|}{ Dutch (ref.) } \\
\hline Foreign & $-1.03^{* * * *}$ & 0.29 \\
\hline \multicolumn{3}{|l|}{ Social demographics } \\
\hline \multicolumn{3}{|l|}{ Netherlands (ref.) } \\
\hline Morocco & -0.10 & 0.34 \\
\hline Netherlands Antilles & $-1.02^{* * *}$ & 0.30 \\
\hline Suriname & -0.40 & 0.24 \\
\hline Turkey & 0.00 & 0.27 \\
\hline European country & $-0.72^{*}$ & 0.28 \\
\hline Other non-Western country & $-0.49^{*}$ & 0.23 \\
\hline Other Western country & $-0.56^{*}$ & 0.24 \\
\hline Unknown country & $-1.21^{*}$ & 0.58 \\
\hline Age & $0.02^{* * * *}$ & 0.00 \\
\hline Female & $0.71^{* * * *}$ & 0.15 \\
\hline \multicolumn{3}{|l|}{ Criminal history } \\
\hline No. of convictions & $-0.05^{* * *}$ & 0.01 \\
\hline Prior prison sentence & $-1.01^{* * * *}$ & 0.10 \\
\hline \multicolumn{3}{|l|}{ Case characteristics } \\
\hline No. of crimes & $-0.42^{* * *}$ & 0.05 \\
\hline \multicolumn{3}{|l|}{ Mild case (ref.) } \\
\hline Severe case & $-1.22^{* * * *}$ & 0.22 \\
\hline Very severe case & $-3.63^{* * * *}$ & 0.38 \\
\hline Constant & $4.48^{* * *}$ & 0.41 \\
\hline
\end{tabular}

(continued)
Table 4. (Continued)

\begin{tabular}{lcc}
\hline & b & SE \\
\hline Offense effects? & Yes & \\
District effects? & Yes & \\
Log pseudolikelihood & $-9,389.47$ &
\end{tabular}

*P $<0.05$

$* *<0.01$

$* * *<0.001$. Standard errors are clustered by district. Model includes controls for 14 different offense types and 20 district-specific effects.

nationals at multiple stages in case processing. These results are not explained by differences in observable characteristics of the crime nor by the defendants' criminal history. To test the robustness of these findings, we reproduce our main results in the Supplementary Appendix using propensity matching as an alternative estimation framework (see Supplementary Tables SA2 and SA3). There we find that regardless of how we account for observable characteristics, unexplained punishment gaps remain. What explains these disparities? The following section draws on interview data to examine the mechanisms underlying these discrepancies.

\section{Qualitative Results}

\section{Annoyance, Logistics, and the Changing Goals of Punishment}

Our interviews identified several sentiments that elucidate the decision-making processes driving the quantitative findings. In line with the idea of 'double punishment', multiple actors expressed annoyance or resentment about immigrant criminality, particularly if they perceived noncitizens coming for the purpose of committing crime. The following quote from a prosecutor captures this idea well:

'And shoplifting by a group of Romanians will be punished differently [than] a single shoplifting by a single person here in the Netherlands because, yeah, if someone takes the effort to come all the way from Romania... and often what you see is they come only with the purpose to actually go shoplifting or pickpocketing. . .it's punished differently.'

Several judges echoed this view:

'if they are here only for a short time, and they have a huge criminal record already, and they can't give me any clue what they were doing here legally, then yeah. That will give a heavier sentence, for sure.' [Judge] 
Table 5. Citizenship-country of origin joint effects on the decision to incarcerate.

\begin{tabular}{|c|c|c|c|c|c|c|c|c|c|}
\hline \multirow[b]{4}{*}{ Variables } & \multicolumn{3}{|c|}{ Model 1} & \multicolumn{3}{|c|}{ Model 2} & \multicolumn{3}{|c|}{ Model 3} \\
\hline & \multicolumn{3}{|c|}{ Incarceration } & \multicolumn{3}{|c|}{ Incarceration } & \multicolumn{3}{|c|}{ Incarceration - foreign born } \\
\hline & \multicolumn{3}{|c|}{$(N=11,820)$} & \multicolumn{3}{|c|}{$(N=11,878)$} & \multicolumn{3}{|c|}{$(N=3.577)$} \\
\hline & b & SE & OR & $\mathbf{b}$ & SE & OR & b & SE & OR \\
\hline \multicolumn{10}{|l|}{ Citizenship status } \\
\hline \multicolumn{10}{|l|}{ Dutch (ref.) } \\
\hline EU foreign national & 1.50 & 0.14 & $4.48^{* * * *}$ & & & & & & \\
\hline Non-EU foreign national & 1.16 & 0.22 & $3.19^{* * * n}$ & & & & & & \\
\hline Foreign & & & & & & & 1.00 & 0.28 & $2.71^{* * * *}$ \\
\hline \multicolumn{10}{|l|}{ Citizenship-country of origin } \\
\hline \multicolumn{10}{|l|}{ Dutch-Netherlands (ref.) } \\
\hline Dutch-Morocco & & & & 0.46 & 0.51 & 1.58 & & & \\
\hline Dutch-Netherlands Antilles & & & & 0.93 & 0.30 & $2.53^{* * *}$ & & & \\
\hline Dutch-Suriname & & & & 0.30 & 0.24 & 1.35 & & & \\
\hline Dutch-Turkey & & & & 0.38 & 0.26 & 1.46 & & & \\
\hline Dutch-European country & & & & -0.29 & 0.57 & 0.75 & & & \\
\hline Dutch-non-Western country & & & & 0.40 & 0.17 & $1.49^{*}$ & & & \\
\hline Dutch-Western country & & & & 0.13 & 0.39 & 1.14 & & & \\
\hline Foreign-Netherlands & & & & 0.39 & 0.51 & 1.48 & & & \\
\hline Foreign-Morocco & & & & 0.70 & 0.33 & $2.01^{*}$ & & & \\
\hline Foreign-Suriname & & & & 1.69 & 0.47 & $5.42^{* * * *}$ & & & \\
\hline Foreign-Turkey & & & & 0.60 & 0.27 & $1.82^{*}$ & & & \\
\hline Foreign-European country & & & & 1.81 & 0.13 & $6.11^{* * *}$ & & & \\
\hline Foreign-non-Western country & & & & 1.62 & 0.41 & $5.05^{* * *}$ & & & \\
\hline Foreign-Western country & & & & 1.74 & 0.24 & $5.70^{* * * * *}$ & & & \\
\hline \multicolumn{10}{|l|}{ Country of origin } \\
\hline Unknown country & & & & 2.18 & 0.33 & $8.85^{* * *}$ & ref. & ref. & ref. \\
\hline Morocco & & & & & & & -0.89 & 0.39 & $.41^{*}$ \\
\hline Netherlands Antilles & & & & & & & -0.07 & 0.64 & .93 \\
\hline Suriname & & & & & & & -0.70 & 0.61 & .50 \\
\hline Turkey & & & & & & & -1.07 & 0.55 & .34 \\
\hline European country & & & & & & & -0.40 & 0.36 & .67 \\
\hline Other non-Western country & & & & & & & -0.65 & 0.53 & .52 \\
\hline Other Western country & & & & & & & -0.58 & 0.50 & .56 \\
\hline
\end{tabular}

$* P<0.05$

$* *<0.01$

$* * * 0.001$. Standard errors are clustered by district. Models estimated using logistic regression and include all variables shown in Table 3 plus controls for district and offense type.

'I see that it happens. Traveling people who only come here to commit a crime, and you mainly see it because they have been in the country for only one week, and they already have committed one or more crimes. And I take offense to that, yes. I think that is - I think it's worse than someone who has lived here for a couple of years, and for whatever reason commits a crime. So it's a factor I take in consideration when I give someone a penalty. But it's not necessary that they will get a higher sentence, but more likely to get a prison sentence than other community service or whatever.' [Judge]
This latter quote is particularly illuminating for our findings. Not only does it directly link national membership to harsher punishment, but it also explains why we find little evidence of sentence length differences once we account for disparities at the incarceration stage. As the judge describes, non-citizen criminality appears to matter in whether they consider incarceration, not for how long.

Even more so than an annoyance, many prosecutors and judges underscored the unique logistical problems involving foreign nationals. On this point, the 
Table 6. Zero-inflated negative binomial model of sentence length accounting for pretrial detention $(N=11,878)$

\begin{tabular}{|c|c|c|}
\hline & $b$ & SE \\
\hline \multicolumn{3}{|l|}{ Count model } \\
\hline \multicolumn{3}{|l|}{ Citizenship status } \\
\hline \multicolumn{3}{|l|}{ Dutch (ref.) } \\
\hline Foreign & -0.17 & 0.16 \\
\hline \multicolumn{3}{|l|}{ Social demographics } \\
\hline \multicolumn{3}{|l|}{ Netherlands (ref.) } \\
\hline Morocco & 0.36 & 0.31 \\
\hline Netherlands Antilles & -0.24 & 0.13 \\
\hline Suriname & -0.14 & 0.09 \\
\hline Turkey & 0.20 & 0.16 \\
\hline European country & 0.11 & 0.22 \\
\hline Other non-Western country & 0.30 & 0.19 \\
\hline Other Western country & 0.23 & 0.21 \\
\hline Unknown country & -0.10 & 0.34 \\
\hline Age & $0.01^{*}$ & 0.00 \\
\hline Female & $-0.39^{* * *}$ & 0.13 \\
\hline \multicolumn{3}{|l|}{ Criminal history } \\
\hline No. of convictions & 0.00 & 0.01 \\
\hline Prior prison sentence & 0.21 & 0.11 \\
\hline \multicolumn{3}{|l|}{ Case characteristics } \\
\hline Pretrial detention & $-0.26^{*}$ & 0.13 \\
\hline No. of crimes & $0.13^{* * * * *}$ & 0.03 \\
\hline \multicolumn{3}{|l|}{ Mild case (ref.) } \\
\hline Severe case & 0.23 & 0.52 \\
\hline Very severe case & $1.38^{* * *}$ & 0.52 \\
\hline Constant & $2.60^{* * * *}$ & 0.69 \\
\hline \multicolumn{3}{|l|}{ Zero-inflated model } \\
\hline \multicolumn{3}{|l|}{ Citizenship status } \\
\hline \multicolumn{3}{|l|}{ Dutch (ref.) } \\
\hline Foreign & $-0.78^{*}$ & 0.34 \\
\hline \multicolumn{3}{|l|}{ Social demographics } \\
\hline \multicolumn{3}{|l|}{ Netherlands (ref.) } \\
\hline Morocco & -0.17 & 0.43 \\
\hline Netherlands Antilles & $-0.89^{* * * *}$ & 0.22 \\
\hline Suriname & -0.37 & 0.20 \\
\hline Turkey & -0.29 & 0.27 \\
\hline European country & $-0.81^{*}$ & 0.33 \\
\hline Other non-Western country & $-0.52^{*}$ & 0.24 \\
\hline Other Western country & $-0.70^{*}$ & 0.27 \\
\hline Unknown country & $-1.69^{*}$ & 0.65 \\
\hline Age & $0.01^{*}$ & 0.00 \\
\hline Female & $0.79^{* * * *}$ & 0.15 \\
\hline \multicolumn{3}{|l|}{ Criminal history } \\
\hline No. of convictions & $-0.05^{* \cdots *}$ & 0.01 \\
\hline Prior prison sentence & $-1.02^{* * * *}$ & 0.11 \\
\hline \multicolumn{3}{|l|}{ Case characteristics } \\
\hline Pretrial detention & $-3.23^{* * * *}$ & 0.13 \\
\hline No. of crimes & $-0.27^{* \cdots * *}$ & 0.06 \\
\hline \multicolumn{3}{|l|}{ Mild case (ref.) } \\
\hline Severe case & $-0.99^{* * * *}$ & 0.17 \\
\hline
\end{tabular}

(continued)
Table 6. (Continued)

\begin{tabular}{lcc}
\hline \multicolumn{2}{c}{$b$} & SE \\
\hline \multicolumn{1}{c}{ Very severe case } & $-2.63^{* * * *}$ & 0.25 \\
Constant & $4.50^{* * *}$ & 0.28 \\
Offense effects? & Yes & \\
District effects? & Yes & \\
Log pseudolikelihood & $-8,955.75$ \\
\hline & & \\
$* P<0.05$ & \\
$* *<0.01$ & \\
$* * *<0.001$. Standard errors are clustered by district. Model includes con- & \\
trols for 14 different offense types and 20 district-specific effects.
\end{tabular}

difficulties posed by the lack of an address in the Netherlands was a prominent theme. As one prosecutor explained:

'If somebody does not have a permanent address. If somebody has just arrived in the Netherlands and he, for example, does not have any money, it is difficult to impose a fine... So you see that you always have to take that into account.'

For many of our respondents, lack of residency often meant taking community sanctions out of consideration because these less coercive punishments were either implausible or impractical.

'we don't give [community service] to people that don't live in the Netherlands, because one of the conditions for the...the probation officer is that he can reach someone on a certain address or a certain phone number. And if someone lives abroad, well, that's not possible, and furthermore, if someone doesn't perform his community service, he will go to prison instead. But that only works in the Netherlands. [Judge]

It's difficult for non-Dutch people to do some working sentence or some learning sentence. So you see it, and most of the time...we send them to jail.' [Prosecutor]

'someone from Azerbaijan won't be able to pay a fine. He won't be able to do the public service with working. So then you go to the next step, and it will be prison.' [Judge]

Language barriers also presented a logistical burden for alternative sanctions because it makes 'it more difficult to perform a community service' [Judge]. Along the same lines, a judge informed us that 'for me, if I have someone who only speaks Turkish or Arabic or Chinese, I don't think about working for a community'. 
Consistent with the description of 'bordered penality', the consideration of logistical elements had the practical effect of undermining one of the central goals of contemporary punishment-reintegration. The following quotes illustrate:

'... one of the goals of punishment is resocialization in the Netherlands...So maybe you are more inclined for someone who lives here to take that more into perspective than someone who comes here to commit a crime, or who's leaving the country afterwards. And then, more - the retribution argument is more to the front.' [Judge]

'of course, that a foreigner who is not known to anyone and who will probably leave the Netherlands in a week or so... Yes, it is harder to come up with something meaningful, if you know what I mean... . So punishment is often the only option.' [Prosecutor]

At times, the lack of rehabilitative potential linked to the issue of deportation, as illustrated by the following judge: for a non-citizen 'involved with opium crimes, which often goes hand in hand with violence and possession of weapons...he will in the end be deported, so there is no reason for rehabilitation.' However, most respondents stressed that they rarely knew whether foreign defendants living in the Netherlands would eventually be deported, as removal decisions remain outside their purview. Thus, reintegration was dismissed primarily when foreign defendants lacked sufficient ties to the Netherlands (e.g. residency).

In several instances, not only did lacking residency in the Netherlands undermine the goal of resocialization, but it also triggered an additional goal of punishment; one exclusively reserved for non-state members-a deterrent from returning.

'Well, I wouldn't sentence someone to only a suspended sentence. Partly suspended I do, because if they leave the Netherlands after their sentence, I don't want them to come back to commit crimes. So therefore, I also give them partly a suspended sentence. But I also give them an - unconditional sentence. And if they didn't have the idea that they only come to the Netherlands to commit a crime, well, then it's not only to prevent them from committing other crime, but in this sense, not to invite them back.' [Judge]

'. . . if people are Dutch nationals, it feels like it's also our responsibility to solve the problem. But if people are coming from abroad with the only purpose of committing crime and go on with their lives somewhere else, it doesn't really feel like our problem. And the only thing, then, what you want to do is to keep those problems out of your country by punishing harshly'. [Judge].

These quotes are notable for two reasons. First, they highlight national membership as a salient division between Dutch officials and non-Dutch defendants (i.e. non-Dutch nationals are not our responsibility). Second, they demonstrate how the goals of punishment are transformed at the intersection of immigration and criminal law. Deterrence of criminal behaviour is a central aim of nearly all sanctioning regimes, but deterrence from returning represents a distinct form of non-citizen justice. In this regard, our interviews provide an instructive example of bordered penality, where the objective is not only to avert criminality, but to prevent foreign nationals from coming back.

\section{The Role of Pretrial Detention}

The link between foreign nationality and pretrial detention emerged as a recurring theme in our interviews. At this early stage of case processing, the flight risk posed by many foreign nationals was referenced often. As the following judge explained:

So yeah, unfortunately, for [noncitizens], pretrial detention is a way to keep them in our influence, in our scope...the idea is that if we let them go in the pretrial phase...they are lost. We cannot find them.

Informed by these insights, we examine the role of pretrial detention in explaining our quantitative findings. Table 6 replicates the ZINB sentence length estimates while accounting for the influence of pretrial detention. Two findings stand out. First, pretrial detention substantially diminishes the likelihood of a nonprison sanction $(b=-3.23, P<0.001)$ but is associated with shorter terms of incarceration $(b=-0.26$, $P<0.05)$. These findings are unsurprising given that judges are legally required to subtract the term of detention from the sentence when imposing a prison sanction (see Art. 27 Penal Code). As one judge explained to us: '...if someone has been in pre-trial detention, my options are more limited, because I can't give someone a suspended sentence, because he has served his time already.' Second, though a significant unexplained gap remains, pretrial detention does partially account for some of the observed citizenship disparities. Comparing the citizenship findings in Tables 4 and 6, pretrial 
detention accounts for approximately a quarter of the sentencing gap in the incarceration equation.

There are two interpretations for this finding. One suggests that pretrial detention captures key case and offense differences between Dutch and non-Dutch citizens, and thus may be an important 'control' measure. The second suggests that pretrial detention reflects yet another case 'outcome' where foreign nationals are disadvantaged. We attempt to adjudicate between these views by modelling the determinants of pretrial detention in Table 7 and the results align more with the latter interpretation. ${ }^{14}$ All else equal, the odds of detention are nearly three times higher for foreign nationals. This finding aligns with the view that regardless of their criminal behaviour or offense history, foreign nationals are less likely to be released pending adjudication. This suggests that in addition to the referral and conviction stages, pretrial detention represents an early case decision where foreign nationals receive more punitive treatment, ultimately yielding a substantially higher likelihood of imprisonment.

\section{Discussion}

Although research is increasingly drawing attention to the dramatic growth of foreign nationals incarcerated throughout Europe, our knowledge about the treatment of non-citizens throughout criminal processing is limited. Our study sought to fill this gap by leveraging a unique combination of data from the Netherlands that addresses two key shortcomings in prior work: (i) the lack of information prior to conviction and (ii) the heavy reliance on statistical data alone.

Regarding the first concern, we use rich linked data that follows criminal cases from arrest through sentencing to address the sample selection issues that have pervaded previous research. In doing so, the present study is among the first to systematically assess the punishment of foreign nationals in the earliest stages of a criminal case as well as the aggregate unexplained disparity throughout case processing. Our analysis suggests these earlier decisions are critical for understanding the disparate treatment of foreign nationals. Compared to Dutch citizens arrested for similar conduct and with the same prior records, non-citizens are more likely to have their cases referred to court, to be detained, and convicted. None of these outcomes would be captured in traditional sentencing analyses and thus have been undervalued in previous research. The disparate treatment of non-citizens in these preceding stages culminate in sizeable differences in the likelihood of incarceration. By our estimates, the probability of incarceration for
Table 7. Logistic regression model of pretrial detention $(N=9,580)$

\begin{tabular}{|c|c|c|c|}
\hline Variables & $b$ & SE & OR \\
\hline \multicolumn{4}{|l|}{ Citizenship status } \\
\hline \multicolumn{4}{|l|}{ Dutch (ref.) } \\
\hline Foreign & 1.07 & 0.25 & $2.90^{* * * * *}$ \\
\hline \multicolumn{4}{|l|}{ Social demographics } \\
\hline \multicolumn{4}{|l|}{ Netherlands (ref.) } \\
\hline Morocco & -0.03 & 0.29 & 0.97 \\
\hline Netherlands Antilles & 0.75 & 0.47 & 2.12 \\
\hline Suriname & 0.33 & 0.32 & 1.39 \\
\hline Turkey & -0.34 & 0.53 & 0.71 \\
\hline European country & 0.39 & 0.29 & 1.47 \\
\hline Other non-Western country & 0.34 & 0.23 & 1.41 \\
\hline Other Western country & 0.13 & 0.26 & 1.14 \\
\hline Unknown country & -0.31 & 0.54 & 0.73 \\
\hline Age & -0.02 & 0.00 & $0.98^{* \cdots * *}$ \\
\hline Female & -0.41 & 0.13 & $0.66^{* * *}$ \\
\hline \multicolumn{4}{|l|}{ Criminal history } \\
\hline No. of convictions & 0.04 & 0.01 & $1.04^{* * * *}$ \\
\hline Prior prison sentence & 0.63 & 0.16 & $1.88^{* * * *}$ \\
\hline \multicolumn{4}{|l|}{ Case characteristics } \\
\hline No. of crimes & 0.46 & 0.04 & $1.58^{* * * *}$ \\
\hline \multicolumn{4}{|l|}{ Mild case (ref.) } \\
\hline Severe case & 1.55 & 0.47 & $4.69^{* * *}$ \\
\hline Very severe case & 4.14 & 0.55 & $62.91^{* * n}$ \\
\hline Offense effects?District effects? & & YesYes & \\
\hline Constant & -5.49 & 0.72 & $0.00^{* * * *}$ \\
\hline$R^{2}$ & 0.32 & & \\
\hline \multicolumn{4}{|l|}{$* P<0.05$} \\
\hline \multicolumn{4}{|l|}{$* * 0.01$} \\
\hline
\end{tabular}

noncitizens upon arrest is 2.6 times higher than similarly situated Dutch citizens, ${ }^{15}$ suggesting that part of the overrepresentation of foreign nationals in Dutch prisons is due to unequal treatment after entering the justice system. These findings take on added significance when considered alongside mounting evidence that foreign nationals are more likely to encounter the police in the first place (van der Woude and van der Leun, 2017). Therefore, not only are non-citizens more likely to enter the criminal justice system, but they receive harsher sanctions at many of the subsequent stages of case processing.

Our interviews revealed multiple mechanisms that explicate these more punitive sanctions. In this respect, our analysis responded to growing demands for research to move beyond documenting whether disparities exist to examining the 'underlying processes that lead to 
observed disparity in criminal sentencing' (van Wingerden, van Wilsem and Johnson, 2016: p. 128). Consistent with Sayad's (2004) description of 'double punishment,' both prosecutors and judges expressed annoyance that noncitizens would compound their status by committing crimes. This sentiment was most acute when they believed these offenders had no other legitimate purpose in the country. In addition, according to multiple judges and prosecutors, the lack of a permanent residence made community and work penalties impractical for many foreign defendants. This had the effect of not only limiting non-incarceration options but also altering the goals of punishment. This occurred along two key dimensions. First, despite the fact that reintegration represents a fundamental principle in both EU and Dutch law, several of our respondents understood this to be conditional on national membership. That is, reintegration and rehabilitation were relevant considerations for Dutch citizens, but moot for many foreign nationals. Second, the case processing of noncitizens introduced a novel goal into the Dutch courts-a deterrent to re-entry. In this regard, the merger of criminal and immigration concerns produced a distinct conception of non-citizen justice; one predicated not on deterring criminality, but on keeping foreign offenders out of the country.

Collectively, our findings have important implications for understanding national membership as an emerging axis of legal inequality. Not only does lacking state membership appear to influence criminal justice decision-making but it does so in ways that are somewhat distinct from other defendant statuses. Much of the punishment literature suggests that factors such as race or national origin affect decision-making by operating in the background of legally relevant considerations (e.g. assessments of risk). Our results suggest that, unlike these statuses, citizenship can operate at the fore of decision-making. That is, prosecutors and judges were not just using national membership as a 'proxy' for attributing negative qualities, but as an explicit status that is deserving of increased punishment. The resentment expressed towards foreign nationals coming for the purpose of criminality illustrates this best. In the same vein, the goal of preventing return migration applies exclusively to foreign nationals. Combined, these direct and exclusive links help explain the persistent punishment disparities throughout case processing and further underscores why national membership is not reducible to national origin.

Though the current study goes considerably beyond prior work, our contributions to the sociological study of citizenship, punishment, and inequality must be considered alongside some limitations. Our analysis represents an initial exploration of heterogeneity within and between citizens and noncitizens, but it is hardly exhaustive. A critical next step is to study the extent to which other offender attributes such as race, ethnicity, and legal status condition the observed citizenship disparities. In the same vein, researchers should examine the role of criminal stereotyping in why judges and prosecutors discussed certain immigrant groups over others (e.g. Romanian shoplifters). Future work using more comprehensive details of defendants' life circumstances is also needed. For instance, our interviews suggest that a lack of permanent residency in the Netherlands factored prominently for prosecutors and judges when dealing with many foreign nationals. However, residency status is rarely collected in criminal justice databases. Given the salience of this logistical issue for many of our respondents, we think it is likely that the inclusion of residency measures would mediate a substantial portion of the unexplained disparities between Dutch and foreign nationals. Related to this point, future research should also explore how the punishment of foreign nationals has changed over time. This call is especially pertinent given the unprecedented refugee crisis throughout Europe and recent decisions by the Dutch Supreme Court which ruled that a lack of a permanent residence in the Netherlands does not disqualify foreign nationals from receiving community sanctions (see ECLI: NL: HR: 2019: 1066 and ECLI: NL: PHR: 2018: 1237). Residential status factored prominently in our interviews and thus researchers would do well to monitor the punishment of non-citizens in the coming years in light of these rulings.

With these caveats and calls for future research in mind, our study documents significant disparities between Dutch citizens and foreign nationals throughout criminal case processing, thus aligning with recent arguments that 'border control objectives are fundamentally reshaping the nature of penal power in most Western societies' (Aas, 2014: p. 536). Moreover, our results call for greater theoretical and empirical breadth within the scholarship on punishment and inequality, which remains primarily focused on internal divisions within society. With roughly 40 million noncitizens residing in the EU and the criminal justice system playing an everlarger role in enforcing both internal and external borders, the punishment of foreign nationals may be redefining the character of legal inequality throughout Europe. 


\section{Supplementary Data}

Supplementary data are available at ESR online.

\section{Acknowledgements}

An earlier version of this article was presented at the 2019 Cultures of Sentencing \& Penal Decision-Making in Europe Conference in Prague. We thank the Research and Documentation Centre of the Dutch Ministry of Justice and the Dutch Public Prosecutors Office for facilitating access to the data and for providing advice on their use. We further thank the Council of the Dutch Judiciary, Lisan Wösten at the Public Prosecutors office in the Hague, and Marc van Nimwegen at the Public Prosecutors Office in Rotterdam for granting permission to conduct interviews with judges and prosecutors.

\section{Funding}

Financial support was provided by The Netherlands Organisation for Scientific Research (451-17-018) and by a Global Synergy Research Grant from Purdue University.

\section{References}

Aas, K. F. (2014). Bordered penality: precarious membership and abnormal justice. Punishment \& Society, 16, 520-541.

Aas, K. F. and Bosworth, M. (2013). The Borders of Punishment: Migration, Citizenship, and Social Exclusion. Oxford: Oxford University Press.

Aebi, M. F. et al. (2018). Foreign Offenders in Prison and Probation in Europe. Strasbourg, Switzerland: Council of Europe Annual Penal Statistics.

Barker, V. (2012). Global mobility and penal order: criminalizing migration, a view from Europe. Sociology Compass, 6, 113-121.

Barker, V. (2013). Democracy and deportation: why membership matters most. In Aas, K. F. and Bosworth, M. (Eds). The Borders of Punishment: Migration, Citizenship, and Social Exclusion. Oxford: Oxford University Press, pp. 237-256.

Bloemraad, I. (2017). Does citizenship matter? In Shachar, A., Baubock, R., Bloemraad, I. and Vink, M. (Eds) The Oxford Handbook of Citizenship. Oxford: Oxford University Press, pp. 524-550.

Boone, M. and Kox, M. (2012). What works for irregular migrants in the Netherlands? European Journal of Probation, 4, 54-68.

Bosworth, M. (2011). Deportation, detention and foreign-national prisoners in England and Wales. Citizenship Studies, 15, 583-595.

Bosworth, M. (2019). Immigration detention, punishment and the transformation of justice. Social \& Legal Studies, 28, 81-99.
Bosworth, M. and Kaufman, E. (2011). Foreigners in a carceral age: immigration and imprisonment in the United States”. Stanford Law \& Policy Review, 22, 429-454.

Cameron, A. C. and Trivedi, P. K. (2013). Regression Analysis of Count Data, 2nd edn. New York: Cambridge University Press.

Kaufman, E. (2018). Epilogue: when citizenship means race. In Bosworth, M., Parmer, A. and Vazquez, Y. (Eds). Race, Criminal Justice, and Migration Control. Oxford: Oxford University Press, pp. 245-249.

Light, M. T. (2016). The punishment consequences of lacking national membership in Germany, 1998-2010. Social Forces, 94, 1385-1408.

Light, M. T. (2017). Punishing the 'Others': citizenship and state social control in the United States and Germany. European Journal of Sociology, 58, 33-71.

Light, M. T., Massoglia, M. and King, R. D. (2014). Citizenship and punishment: the salience of national membership in U.S. criminal courts. American Sociological Review, 79, 825-847.

Long, J. S. (1997). Regression Models for Categorical and Limited Dependent Variables. Thousand Oaks, CA: SAGE Publications.

Sayad, A. (2004). The Suffering of the Immigrant. Cambridge: Polity Press.

Steffensmeier, D., Ulmer, J. and Kramer, J. (1998). The interaction of race, gender, and age in criminal sentencing: the punishment cost of being young, black, and male. Criminology, 36, 763-798.

Tak, P. J. (2008). The Dutch Criminal Justice System. Nijmegen: Wolf Legal Publishers.

Unnever, J. D. (2018). Ethnicity and crime in the Netherlands. International Criminal Justice Review, 29, 187-204.

United Nations, Department of Economic and Social Affairs, Population Division. (2017). International Migration Report 2017: Highlights (ST/ESA/SER.A/404).

van der Woude, M., van der Leun, J. and Nijland, J.-A. A. (2014). Crimmigration in the Netherlands. Law \& Social Inquiry, 39, 560-579.

van der Woude, M. and van der Leun, J. (2017). Crimmigration checks in the internal border areas of the EU: finding the discretion that matters. European Journal of Criminology, 14, 27-45.

van Kalmthout, A. M., Hofstee-van der Meulen, F. B. A. M. and Dünkel, F. (Eds). (2007). Foreigners in European Prisons. Oisterwijk: Wolf Legal Publishers.

van Wingerden, S., van Wilsem, J. and Johnson, B. D. (2016). Offender's personal circumstances and punishment: toward a more refined model for the explanation of sentencing disparities. Justice Quarterly, 33, 100-133.

Wermink, H. T. et al. (2015). Expanding the scope of sentencing research: determinants of juvenile and adult punishment in the Netherlands. European Journal of Criminology, 12, 739-768. 
Wermink Hilde, T. et al. (2018). Studying ethnic disparities in sentencing: the importance of refining ethnic minority measures. In Ulmer J. T. and Bradley M. S. (Eds) Handbook on Punishment Decisions: Locations of Disparity. New York: Routledge, pp. 239-264.

Michael Light is Associate Professor of Sociology at the University of Wisconsin-Madison. His research primarily focuses on crime, punishment, and immigration. His recent work has been published in the American Sociological Review, the American Journal of Sociology, and the European Journal of Sociology.

Hilde Wermink is an Associate Professor at the Institute of Criminal Law and Criminology at Leiden University. Her research interests include the determinants of consecutive sentencing decisions, and the effects of imprisonment (and other punishments) on criminal behavior. 